\title{
Suomalaisen kirjallisuudentutkimuksen satoa vuodelta 2014
}

Ameel, Lieven. Helsinki in Early Twentieth-Century Literature. Urban Experiences in Finnish Prose Fiction 1890-1940. Studia Fennica Litteraria 8. Helsinki: SKS.

Ekman, Michel (red.). Finlands svenska litteratur 1900-2012. Helsingfors: Svenska litteratursällskapet i Finland \& Stockholm: Atlantis.

Ekman, Michel (hg.). Finnlands schwedische Literatur 1900-2012. Aus dem Schwedischen von Regine Elsässer. Münster: Kleinheinrich Verlag.

Hakola, Outi \& Sari Kivistö (eds.). Death in Literature. Newcastle: Cambridge Scholars Publishing.

Hakola, Outi, Sari Kivistö ja Virpi Mäkinen (toim.). Kuoleman kulttuurit Suomessa. Helsinki: Gaudeamus.

Helle, Anna \& Juri Joensuu (toim.). Esseitä suomalaisesta kokeellisesta proosasta. Mahdollisen Kirjallisuuden Seura. http://mahdollisenkirjallisuudenseura.net/

Härmänmaa, Marja \& Christoffer Nissen (toim.). Decadence, Degeneration, and the End: Studies in the European Fin de Siècle. New York: Palgrave Macmillan.

Journal of Finnish Studies 18 (2)/2014. Theme issue Finnish Working-class Literature: International Influences and New Research Trends. Guest-edited by Kirsti SalmiNiklander \& Kati Launis.

Jytilä, Riitta. Sorä̈äniä, sitaatteja ja suunnitelmallisuutta. Moniäänisyys Eira Stenbergin romaanituotannossa. Turku: Turun yliopisto.

https://www.doria.fi/handle/10024/94467

Kivistö, Sari. The Vices of Learning. Morality and Knowledge at Early Modern Universities. Sarja: Education and Society in the Middle Ages and Renaissance, vol. 48. Leiden: Brill.

Koho, Satu; Korpua, Jyrki; Rahikkala, Salla \& Sandbacka, Kasimir (toim.). Mahdollinen kirja. Kulttuurintutkimuksen 15. seminaari "Mahdolliset maailmat" Oulun yliopistossa syksyllä 2012. Oulu: Oulun yliopisto.

Maijala, Minna. Herkkä, hellä, hehkuvainen Minna Canth. Helsinki: Otava.

Meretoja, Hanna. The Narrative Turn in Fiction and Theory: The Crisis and Return of Storytelling from Robbe-Grillet to Tournier. Basingstoke \& New York: Palgrave Macmillan. 
Mäkelä, Hanna. Narrated Selves and Others. A Study of Mimetic Desire in Five

Contemporary British and American Novels. Helsinki: Helsingin yliopisto.

http://urn.fi/URN:ISBN:ISBN 978-952-10-9754-6

Nykänen, Elise. Worlds Within and Without. Presenting Fictional Minds in Marja-Liisa

Vartio's Narrative Prose. Helsinki: Helsingin yliopisto.

https://helda.helsinki.fi/handle/10138/152722

Pyrhönen, Heta. Jane Austen aikalaisemme. Helsinki: Avain.

Rajala, Panu. Tulisoihtu pimeä̈̈n. Olavi Paavolaisen elämä. Helsinki: WSOY.

Riikonen, H. K.. Nukuin vasta aamuyöstä. Olavi Paavolainen 1903-1964. Helsinki:

Gummerrus.

Tidigs, Julia. Att skriva sig över språkgränserna. Flerspråkighet i Jac. Ahrenberg och

Elmer Diktonius prosa. Åbo: Åbo Akademis förlag.

http://urn.fi/URN:ISBN:978-951-765-709-9

Luettelo perustuu Avaimen toimitukselle lähetettyibin tietoibin. 